\title{
FRONTAL BONE ANATOMY OF TERATOPHONEUS CURRIEI (THEROPODA: TYRANNOSAURIDAE) FROM THE UPPER CRETACEOUS KAIPAROWITS FORMATION OF UTAH
}

\author{
Chan-gyu Yun
}

Received: 6 August 2021 / Accepted: 18 October 2021 / Published online: 5 November 2021

\begin{abstract}
A right frontal bone belonging to the tyrannosaurid theropod Teratophoneus curriei from the Campanian Kaiparowits Formation of Utah provides important anatomical information that is useful in understanding tyrannosaurid taxonomy and relationships. Many aspects of its anatomy indicate a subadult ontogenetic status of this individual, as they compare favorably with subadults of other tyrannosaurids such as Daspletosaurus torosus and Tyrannosaurus rex. This is consistent with the previous interpretation that this individual was subadult, based on different cranial bones such as lacrimal or maxilla. It is likely that a previous assessment of the body mass of this individual was underestimated, and it is presumed here that it was most likely around $1000 \mathrm{~kg}$. This description of the frontal anatomy has several implications for previous works on tyrannosaurid cranial anatomy, and information that corrects aspects of our understanding on tyrannosaurid frontal anatomy is provided. Reanalysis of Nanuqsaurus hoglundi, a tyrannosaurid theropod that has similar frontal morphology with Teratophoneus curriei, implies that parts of its diagnosis are problematic and the proposed evidence for the supposed diminutive body size of this taxon is weak.
\end{abstract}

Keywords: Frontal, Anatomy, Theropoda, Tyrannosauroidea, Tyrannosauridae, Teratophoneus

\section{INTRODUCTION}

The frontal bone in theropod dinosaurs forms the rostral part of the roof of the braincase. Due to its compact nature, it is preserved more frequently than other cranial elements (e.g., Currie, 1987; Longrich, 2008; Jasinski, 2015; Averianov, 2016). Currie (1987) noted that the frontal bone of theropods is diagnostic at the specific level, and subsequent publications have followed this assertion that frontals are one of the most taxonomically useful elements in the entire theropod skull (Longrich, 2008; Jasinski, 2015; Averianov, 2016; Evans et al., 2017). Tyrannosaurid theropods, a group of gigantic carnivorous dinosaurs that are characterized by large robust skulls with incrassate teeth, short forelimbs with only two functional digits, and elongate hindlimbs with arctometatarsalian pedes (Holtz, 2004; Brusatte et al., 2010; Brusatte \& Carr, 2016), are no exception for this. Diagnoses of recently erected taxa often contain characters from the frontal (Carr \& Williamson, 2010; Carr et al., 2011; Loewen et al., 2013; Carr et al., 2017; Voris et al., 2020), and in some cases even a new taxon was named mainly based on features of this element (Fiorillo \& Tykoski, 2014; McDonald et al., 2018).

Some recent studies acknowledge that the frontal anatomy of tyrannosaurids can be diagnostic to relatively low taxonomic levels ("subfamily", "tribe") but question the utility of several features that have been asserted as unique for some genera and species by previous authors. Currie (2003a) noted the high degree of intraspecific variation in sutures for the prefrontals and the lacrimals in the frontals of Gorgosaurus libratus and Tyrannosaurus rex. Additionally, in their description of specimens of an unnamed tyrannosaurine taxon from the Aguja Formation of Texas that include two frontals, Lehman \& Wick (2012) noted the high degree of ontogenetic and intraspecific variation in tyrannosaurid frontals; they concluded that the morphology of this bone in tyrannosaurids has limited merit in assessing relationships among taxa, especially when the degree of maturity of the individual is not clear. Yun (2020b) mentioned that the autapomorphies proposed for Dynamoterror dynastes - a tyrannosaurine from the Menefee Formation of New Mexico that was named based on frontal anatomy (McDonald et al., 2018) - are present in frontals of Daspletosaurus torosus and Teratophoneus curriei, and suggested that this taxon should be considered as a nomen dubium. Later in the same year, Yun (2020c) described a Daspletosaurus torosus frontal from the Dinosaur Park Formation of Alberta and also argued that there is a high degree of intraspecific variation in the morphology of sutures with adjacent bones (lacrimal, prefrontal) as well as in the rostral extent of the sagittal crest in tyrannosaurid frontals. Based on these observations, Yun (2020b) urged that caution is needed when establishing autapomorphies or diagnoses based on features in tyrannosaurid frontal bones.

Part of these controversies may arise due to an insufficient amount of knowledge about tyrannosaurid frontal anatomy, despite the abundance of this element in the fossil record (Currie, 1987). Whereas detailed descriptions of tyrannosaurid frontals are known (Brochu, 2003; Currie, 2003a; Hurum \& Sabath, 2003; Lehman \& Wick, 2012; Bever et al., 2013; Fiorillo \& Tykoski, 2014; McDonald et al., 2018; Voris et al., 2020; Yun, 2020c; Paulina-Carabajal et al., 2021), they are usually restricted to certain taxa. Other species have only been the subject of brief descriptions on their skeletal anatomy including frontals (Carr \& Williamson, 2010; Carr et al., 2011; 
Loewen et al., 2013; Lü et al., 2014; Carr et al., 2017). Additionally, previous publications about tyrannosaurid frontals either show only limited views of the bone (Brochu, 2003; Currie, 2003a; Hurum \& Sabath, 2003), or else certain frontal features are obscured by their contacts with adjacent bones or by poor preservation (Bever et al., 2013; Fiorillo \& Tykoski, 2014; Voris et al., 2020), and even may contain erroneous interpretations of some features (Lehman \& Wick, 2012; McDonald et al., 2018; Yun, 2020c). Therefore, any new descriptions of tyrannosaurid frontals, especially those from preliminarily described taxa, will be very important in understanding tyrannosaurid frontal anatomy, in order to clarify some of these controversies.

Teratophoneus curriei is a tyrannosaurine theropod from the Kaiparowits Formation (Upper Campanian) of Utah that was first reported and named by Carr et al. (2011). Unfortunately, while the fragmentary skeleton of the holotype was described in an unpublished doctoral thesis by Carr (2005), the formal publication (Carr et al., 2011) only contains brief descriptions of selected elements with a limited amount of illustrations. Loewen et al. (2013) reported two new specimens that are assignable to Teratophoneus curriei, including an individual that preserves a nearly complete skull; but again, the publication is limited to only very general descriptions of certain skeletal parts of these specimens. Titus et al. (2021) reported a tyrannosaurid bonebed from the Kaiparowits Formation, consisting of multiple individuals of different sizes that are possibly referable to Teratophoneus curriei. They mentioned that there is one articulated, undescribed skeleton (UMNH VP 21100) of this taxon available from the locality, but no specimens were described as the geological setting as well as the taphonomy of the bonebed were the main focuses of their work. Thus, insufficient degree of establishment of the anatomy of Teratophoneus curriei in the literature may have led Paul (2016) to synonymise Teratophoneus with Tyrannosaurus. This synonymy has not been accepted by later studies on Tyrannosauridae (Carr et al., 2017; McDonald et al., 2018; Voris et al., 2020; Yun, 2020b, c). In summary, despite the decade-long erection of this taxon and the new discoveries made within the last decade, Teratophoneus curriei remains an understudied tyrannosaurid taxon.

Here, the right frontal bone of the subadult holotype individual of Teratophoneus curriei is described in detail. This is one of the best-preserved elements from the partial skull of this individual (Carr, 2005). Although this element was described in Carr (2005), no detailed description accompanied by accurate illustrations of the frontal of Teratophoneus curriei is available in the formal peer-reviewed literature. Furthermore, a significant amount of new information has become available regarding the morphology and individual variation of tyrannosaurid frontals since the original description of Carr (2005). Additionally, the description of this specimen gives an opportunity to provide a better understanding of tyrannosaurine frontal anatomy, especially in the light of previous errors in the interpretations about certain specimens (Lehman \& Wick, 2012; McDonald et al., 2018; Yun, 2020c).

\section{Institutional abbreviations}

AMNH, American Museum of Natural History, New York, USA; BYU, Brigham Young University, Utah, USA; CM, Carnegie Museum of Natural History, Pennsylvania, USA; DMNH, Perot Museum of Nature and Science, Dallas, Texas, USA; LACM, Los Angeles County Museum of Natural History, Los Angeles, USA; MOR, Museum of the Rockies, Montana, USA; MPC-D, Institute of Paleontology, Mongolian Academy of Sciences, Ulaanbaatar, Mongolia; NMMNH, New Mexico Museum of Natural History and Science, New Mexico, USA; SDNHM, San Diego Natural History Museum, San Diego, USA; SDSM, South Dakota School of Mines and Technology, South Dakota, USA; TMM, Texas Memorial Museum, Texas, USA; TMP, Royal Tyrrell Museum of Palaeontology, Alberta, Canada; UMNH, Utah Museum of Natural History, Salt Lake City, USA; YPM, Yale Peabody Museum of Natural History, Connecticut, USA.

\section{MATERIAL AND METHODS}

The material studied is a part of BYU 8120/9396 (holotype individual of Teratophoneus curriei), and is a nearly complete right frontal. Of note, as already emphasized by Carr et al. (2011) and Loewen et al. (2013), multiple specimen numbers (BYU 13719, 8120/9396, 8120/9397, $826 / 9402$, 9398) were given to different parts of this individual. The present anatomical study is conducted using a high-quality cast and scan of the original specimen, which is housed in the Brigham Young University Museum of Paleontology. The cast was made from a 3D scan shared by museum director Dr. Rodney D. Scheetz, and the figures were generated from this scan. Comparative materials, represented by casts of SDNHM 32701 (Daspletosaurus torosus frontal) and UMNH VP 28348 (frontals of the Dynamoterror dynastes holotype) were generated from a 3D scan shared by the collection manager Kesler Randall of the San Diego Natural History Museum, and scans of UMNH VP 28348 uploaded in Sketchfab by the Western Science Center (https://sketchfab.com/WesternScienceCenter/collections/ dynamoterror-dynastes). Measurements of the right frontal of UMNH VP 20200 (Lythronax argestes holotype) were taken using the program ImageJ (Schneider et al., 2012) based on the published figure by Loewen et al. (2013). "Dynamoterror dynastes" is provisionally regarded as a nomen dubium following Yun (2020b, c), and "Thanatotheristes" is considered as a junior synonym of Daspletosaurus following Yun (2020c). PaulinaCarabajal et al. (2021) considered Daspletosaurus materials (e.g., SDNHM 32701, TMP 1980.016.0924) from the Dinosaur Park Formation as an unnamed new species of this genus, but these are provisionally considered as 
Daspletosaurus torosus in this work, following Carr et al. (2017), as characters that separate these specimens from Daspletosaurus torosus are yet to be sufficiently established. TMP 1994.143.0001 is a tyrannosaurid specimen from the Dinosaur Park Formation with a controversial taxonomic identity, which is either Gorgosaurus (Voris et al., 2019) or Daspletosaurus (Currie, 2003a; PaulinaCarabajal et al., 2021). The conclusion of Voris et al. (2019) that referred this specimen as Gorgosaurus is provisionally followed here, as Daspletosaurus autapomorphies were not yet sufficiently demonstrated in this specimen. The anatomical nomenclature used in this study follows Currie (2003a), Carr et al. (2017), McDonald et al. (2018) and Yun (2020c).

\section{SYSTEMATIC PALAEONTOLOGY}

\author{
TYRANNOSAUROIDEA Osborn, 1906 \\ EUTYRANNOSAURIA Delcourt \& Grillo, 2018 \\ TYRANNOSAURIDAE Osborn, 1906 \\ TYRANNOSAURINAE Osborn, 1906 \\ Teratophoneus Carr et al., 2011 \\ Teratophoneus curriei Carr et al., 2011
}

Material: BYU 8120/9396, which consists of several skull elements of the holotype individual, including the right frontal bone described in this paper.

Horizon and locality: Upper Cretaceous (Campanian) Kaiparowits Formation, Grand Staircase-Escalante National Monument, Utah, USA (Carr et al., 2011).

\section{DESCRIPTION}

Measurements of the specimen described herein were provided in the supplementary information of Carr et al. (2011). This work focuses on comparative redescription of the holotype frontal (BYU 8120/9396, in part) of Teratophoneus curriei compared with newly erected taxa (Loewen et al., 2013; Fiorillo \& Tykoski, 2014; McDonald et al., 2018; Voris et al., 2020) that were not available for comparison at the time of Carr (2005) and Carr et al. (2011); also, these original studies of the taxon did not have the benefit of the large amount of new information concerning the variability and morphology of tyrannosaurid frontals, including those regarding previously described tyrannosaurids (Lehman \& Wick, 2012; Yun, 2020c).

The length of the subcutaneous surface of the dorsal view is $135 \mathrm{~mm}$, and in overall size the frontal of Teratophoneus is comparable to subadult individuals of other North American tyrannosaurids like Albertosaurus sarcophagus, Gorgosaurus libratus, Daspletosaurus torosus, "Dynamoterror dynastes", and Tyrannosaurus rex (Currie, 2003a; McDonald et al., 2018; Yun, 2020c). Given that a tyrannosaurid frontal is morphologically complex (McDonald et al., 2018; Yun, 2020c), the description of BYU 8120/9396 is divided into six sections, detailing the dorsal, lateral, medial, ventral, rostral, and caudal surfaces of the element.

Dorsal surface: As noted by Carr (2005), the rostralmost part of the nasal contact is broken in the specimen, but the subcutaneous surface is very well-preserved (Fig. 1a, b). The subcutaneous surface of the nasal process of BYU $8120 / 9396$ is elongate, and its rostral tip tapers. This is typical for many tyrannosaurid specimens, which usually bear one to three projections that interdigitate with the caudal part of the nasal (Currie, 2003a; Lehman \& Wick, 2012). In one specimen (TMP 1980.016.0924) of Daspletosaurus torosus (Currie, 2003a; Voris et al., 2020), four projections are present (Lehman \& Wick, 2012; erroneously labeled as Gorgosaurus libratus). Furthermore, there are supranumerary projections present in two specimens (NMMNH P-25049, 27469) of Bistahieversor sealeyi (Carr \& Williamson, 2010; Lehman \& Wick, 2012). The nasal process is narrow transversely, as in subadults and adults of derived tyrannosaurines (Carr \& Williamson, 2004, 2010; Yun, 2020c). In Bistahieversor sealeyi, albertosaurines, alioramins, and juveniles of derived tyrannosaurines, this process is wide in dorsal view (Currie, 2003a; Carr \& Williamson, 2010; Lehman \& Wick, 2012; Bever et al., 2013). The subcutaneous surface of the nasal process is generally flat in BYU 8120/9396 (Fig. 1), which differs from Daspletosaurus spp. that has a rostrocaudal ridge on this surface (Carr et al., 2017; Voris et al., 2019, 2020; Yun, 2020c).

Lateral to the nasal process, there is a short $(5 \mathrm{~mm})$, triangular prefrontonasal process that is similar to those of a subadult Daspletosaurus torosus (Yun, 2020c), "Dynamoterror dynastes" (McDonald et al., 2018), and Lythronax argestes (Loewen et al., 2013: fig. 2E). In Tyrannosaurus rex, some specimens lack the prefrontonasal process (Carr, 2020), and this appears to be also true for the left frontal of UMNH VP 16690, a Teratophoneus curriei specimen reported by Loewen et al. (2013: fig. 3E). Laterally, there is an elongate $(21 \mathrm{~mm})$ prefrontolacrimal process (Fig. 1b) that is unique for Teratophoneus curriei and Nanuqsaurus hoglundi (Fiorillo \& Tykoski, 2014; McDonald et al., 2018) but differs from the condition present in most tyrannosaurids that have a short process (e.g., McDonald et al., 2018; Yun, 2020c). In Lythronax argestes, the prefrontolacrimal process is slightly longer than the prefrontonasal process (Loewen et al., 2013: fig. 5C; Voris et al., 2020). However, it is possible that intraspecific variation was present in this region in Teratophoneus curriei, as only a single prong with no rostral divisions (i.e. distinct prefrontonasal and prefrontolacrimal processes) is present in a referred specimen (UMNH VP 16690, Loewen et al., 2013: fig. 3E). The prefrontonasal and prefrontolacrimal processes are closely spaced in dorsal view (Fig. 1B), which is a subadult character in tyrannosaurines (Carr, 2020; Yun, 2020c). In mature tyrannosaurines, the two processes are widely separated (Carr, 2020; Voris et al., 2020: fig. 8; Yun, 2020c). The lacrimal socket faces rostrally, and its medial 


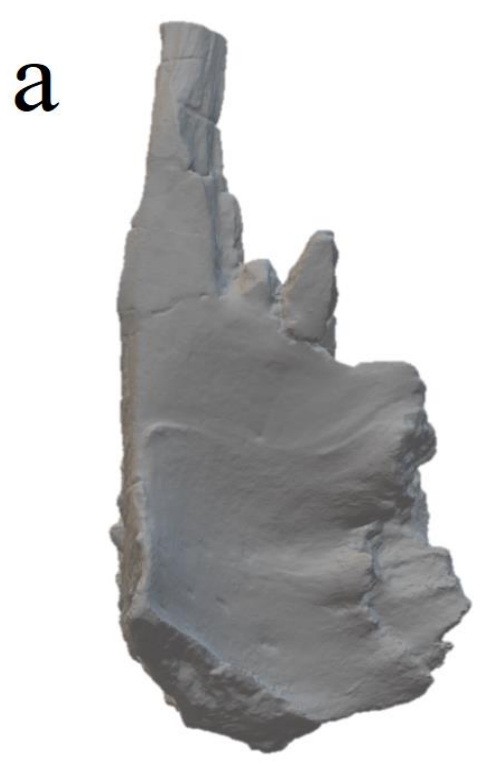

\section{$10 \mathrm{~cm}$}

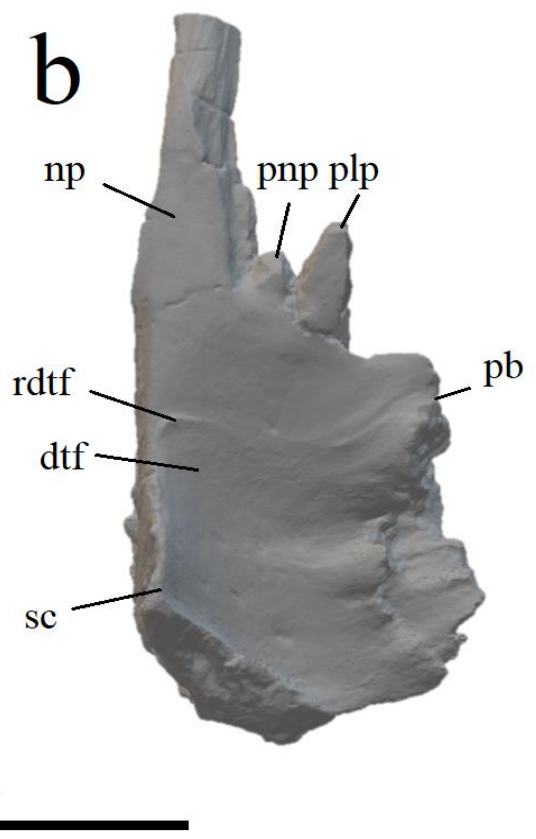

Fig. 1 Stereopair of 3D model of the right frontal of BYU 8120/9396 in dorsal view. Abbreviations: dtf, dorsotemporal fossa; np, nasal process; pb, postorbital buttress; plp, prefrontolacrimal process; pnp, prefrontonasal process; rdtf, rostral margin of the dorsotemporal fossa; sc, sagittal crest.

margin is elongate as in albertosaurines and immature tyrannosaurines (Carr \& Williamson, 2004, 2010). The mediolateral width of the caudal margin is slightly shorter than the length of the medial margin in dorsal view. The angle between the orbital slot and the interfrontal suture is approximately $60^{\circ}$. In BYU $8120 / 9396$, there is no lateral projection that extends further than the orbital slot in the postorbital buttress; thus, it is mediolaterally narrower compared to a similar sized subadult Daspletosaurus torosus (Yun, 2020c). The view of Paul (2016) that the caudal part of the skull in Teratophoneus curriei is extremely broad - comparable to the degree in Tyrannosaurus rex - is not supported in this work. The rostral edge of the dorsotemporal fossa is sinuous (Fig. 1B), as in Gorgosaurus libratus, Lythronax argestes and some Tyrannosaurus rex individuals (Carr et al., 2017). This edge is straight in Daspletosaurus torosus and other Tyrannosaurus rex specimens, and convex in Tarbosaurus bataar (Carr et al., 2017; Yun, 2020c). The dorsotemporal fossa occupies about $50 \%$ of the subcutaneous surface, unlike in adults of Tarbosaurus bataar and Tyrannosaurus rex in which the fossa occupies more than $60 \%$ (Carr et al., 2017; Carr, 2020). The mediolateral width of the caudal shelf is subequal to that of the postorbital buttress. The sagittal crest is tall, undivided in dorsal view as in derived tyrannosaurines that phylogenetically lie outside the Tarbosaurus bataar + Tyrannosaurus rex clade (Carr et al., 2017). The rostrocaudal length of the crest subequals that of dorsotemporal fossa, unlike in some specimens of Daspletosaurus spp. (Voris et al., 2020; Yun, 2020c) and an unnamed tyrannosaurine from the Aguja Formation (Lehman \& Wick, 2012), in which the sagittal crests extend rostral to the dorsotemporal fossae.

Lateral surface: An elongate prefrontolacrimal process covers the dorsal part of the sutural surface for the prefrontal in lateral view and thus, only the ventral part of this suture is visible (Fig. 2a, b). The ventral part of the sutural surface is a process-like projection that is inclined rostroventrally (Fig. 2b), similar to that of Gorgosaurus libratus (Currie, 2003a: fig. 20B, misidentified as Daspletosaurus sp., in this work - Voris et al., 2019) and Lythronax argestes (McDonald et al., 2018: fig. 6H). The medial surface of the lacrimal socket is positioned dorsally, and there is a broad groove that marks its central region. The orbital slot, which separates the lacrimal and postorbital sutures, is narrow, groove-like and nearly vertical with only a slight rostral inclination. However, the slot is not as deep in BYU 8120/9396 as in other tyrannosaurids like Daspletosaurus torosus or Lythronax argestes (Loewen et al., 2013; Yun, 2020c). The ventral part of the groove grades into the orbit. The rostral part of the postorbital suture (caudolateral part of the postorbital buttress) is rectangular and rugose, and its dorsoventral depth is greater than its rostrocaudal length (Fig. 2b). The caudal part of the postorbital suture is also rectangular, but it is much smaller compared to the rostral part. The rostral portion of the caudal part of the postorbital suture extends more laterally compared to the caudal portion. A dorsoventrally deep, rostrocaudally wide groove is present ventrally (Fig. 2b), as in the holotype (UMNH VP 28348) of "Dynamoterror dynastes" (McDonald et al., 2018; Yun, 2020b, c; pers. obs.). In Tyrannosaurus rex and an unnamed tyrannosaurine from the Aguja 

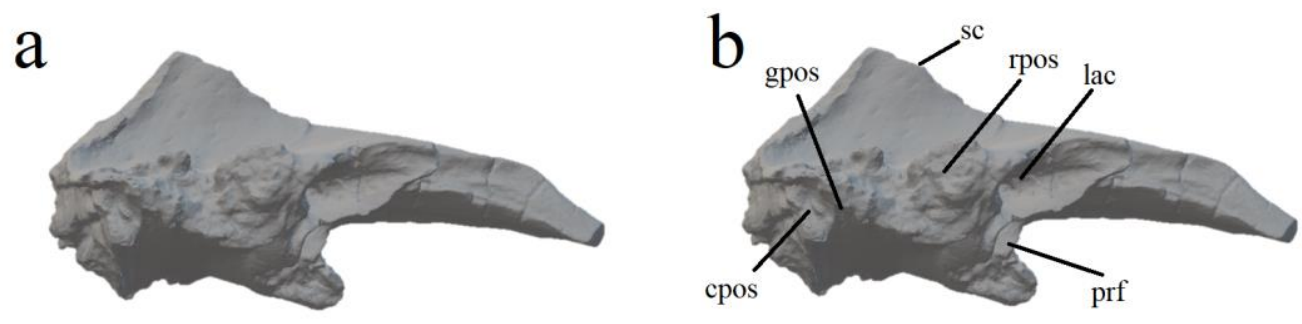

$10 \mathrm{~cm}$

Fig. 2 Stereopair of 3D model of the right frontal of BYU 8120/9396 in lateral view. Abbreviations: cpos, caudal part of postorbital suture; gpos, groove between rostral and caudal parts of postorbital suture; lac, lacrimal socket; prf, joint surface for prefrontal; rpos, rostral part of postorbital suture; sc, sagittal crest.
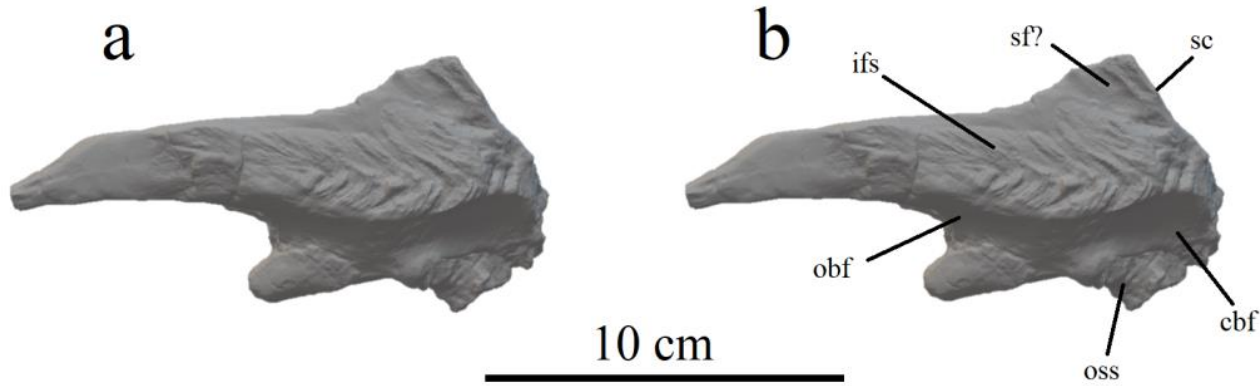

Fig. 3 Stereopair of 3D model of the right frontal of BYU 8120/9396 in medial view. Abbreviations: cbf, cerebral fossa; ifs, interfrontal suture; obf, olfactory bulb fossa; oss, orbitosphenoid suture; sc, sagittal crest; sf?, possible trace of sagittal foramen.

Formation, an open foramen is present in the region instead of groove (Lehman \& Wick, 2012; McDonald et al., 2018; Yun, 2020c). A tall, triangular sagittal crest is easily visible on the dorsocaudal part of the bone.

Medial surface: Most of the medial surface is occupied by the vertical interfrontal suture, and only the rostral third of the medial surface is smooth (Fig. 3a, b). The interfrontal suture is covered with a series of rostrally opening, V-shaped ridges (Fig. 3b), as in other tyrannosaurids (Currie, 2003a: fig. 20; McDonald et al., 2018; Yun, 2020c). The ridges in the caudal part are more distinct compared to those in the rostral part. At mid-height of the sagittal crest, there is a deep, broad rostrocaudal groove that is slightly inclined dorsoventrally, and may mark the path for the sagittal foramen that is present in other tyrannosaurid individuals (Currie, 2003a; Carr \& Williamson, 2004). This was also suggested for the Aguja Formation tyrannosaurine taxon (Lehman and Wick, 2012). Along the ventral edge, parts of the olfactory bulb and cerebral fossae as well as the orbitosphenoid suture are visible (Fig. 3b) in medial view.

Ventral surface: On the ventral surface of the nasal process, there is an elongate narrow depression that housed the caudal extent of the nasal cavity (McDonald et al., 2018; Yun, 2020c). This region would have been lined with olfactory epithelium in tyrannosaurids (Bever et al., 2013). Medial to the caudal extent of the nasal cavity, there is a distinct, ridge-like median septum. In BYU 8120/9396; this is much narrower mediolaterally (Fig. 4a, b) compared to the relatively thick septum known in Daspletosaurus torosus (Yun, 2020c). In the caudolateral part of the nasal cavity, there is an ethmoid scar (Fig. 4b), which is a mediolaterally sloping ridge that separates the nasal cavity from the fossa for the olfactory bulb. Rostrolateral to the ethmoid scar, there is a narrow contact surface for the prefrontal (Fig. 4b), as in other tyrannosaurids (e.g., Lehman \& Wick, 2012: fig. 4d). However, it differs from the broad, complex surface seen in Daspletosaurus spp. (Voris et al., 2020; Yun, 2020c). Apparently, there is only one projection on the caudal part of the surface, which is typical for most tyrannosaurids other than Daspletosaurus degrootorum, which possesses two projections (Voris et al., 2020). The caudomedial part of the prefrontal contact surface forms a rostrolaterally projecting, thick projection referred to as the crista cranii by Ali et al. (2018). The crista cranii in BYU 8120/9396 is more rostrally oriented compared to the orientation in a similar sized subadult Daspletosaurus torosus (Yun, 2020c). Caudal to the crista cranii, there is a medioventrally positioned orbitosphenoid suture that is beanshaped and filled with bumps and depressions as in other tyrannosaurids (McDonald et al., 2018; Yun, 2020c). Lehman \& Wick (2012) misidentified this region as a sinus cavity (discussed later in this paper). Caudoventral to the orbitosphenoid suture, there is a triangular suture for the laterosphenoid (Fig. 4b). 

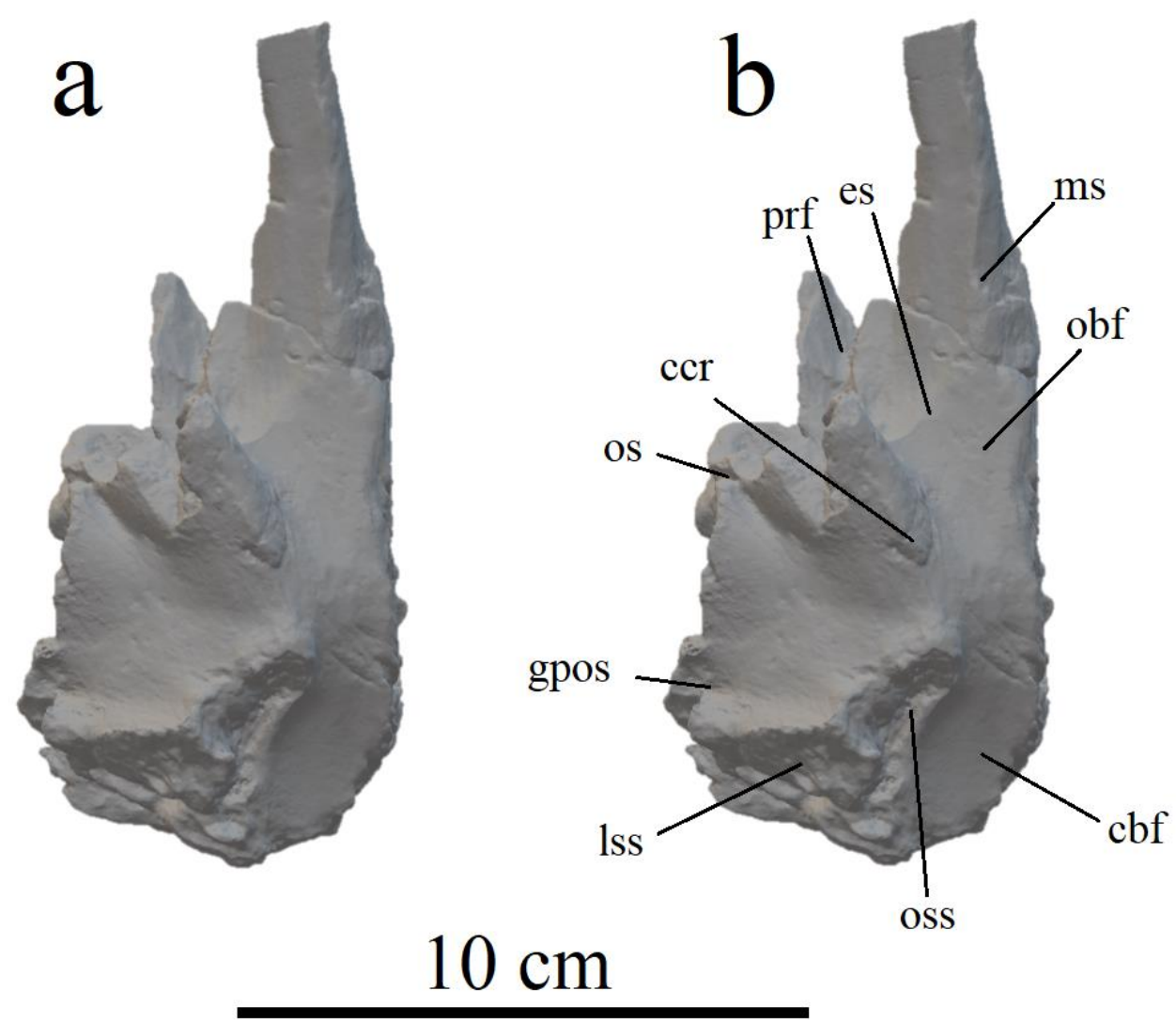

Fig. 4 Stereopair of 3D model of the right frontal of BYU 8120/9396 in ventral view. Abbreviations: cbf, cerebral fossa;ccr, crista cranii; es, ethmoid scar; gpos, groove between rostral and caudal parts of postorbital suture; lss, laterosphenoid suture; ms, median septum; obf, olfactory bulb fossa; os, orbital slot; oss, orbitosphenoid suture; prf, joint surface for prefrontal.

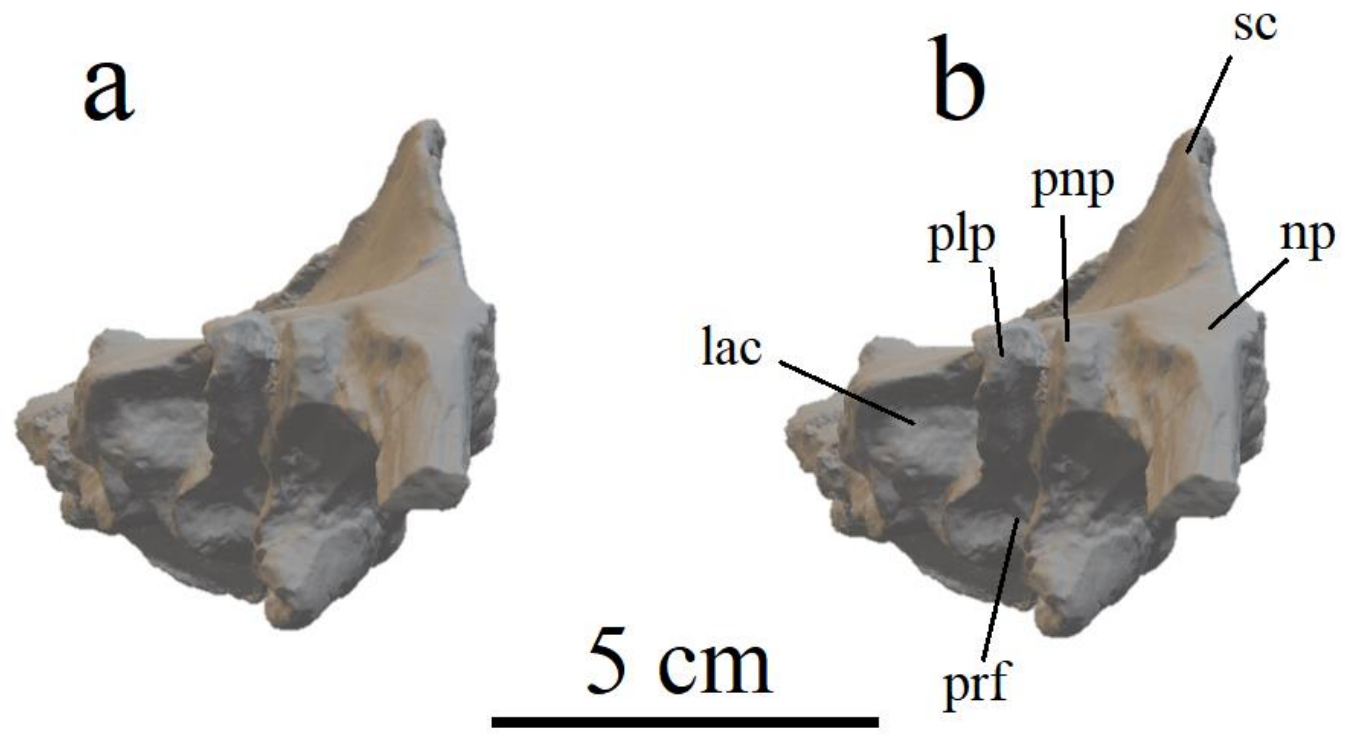

Fig. 5 Stereopair of 3D model of the right frontal of BYU 8120/9396 in rostral view. Abbreviations: lac, lacrimal socket; np, nasal process; plp, prefrontolacrimal process; pnp, prefrontonasal process; prf, joint surface for prefrontal; sc, sagittal crest. 
The orbital wall is large and teardrop-shaped, and is bounded laterally by the crista cranii and the orbitosphenoid suture, and caudally by the laterosphenoid suture. The endocranial region is hourglass shaped, and occupies two-thirds of the medial part of the ventral surface (Fig. 4b). The olfactory bulb fossa is diamondshaped and forms the rostral part of the endocranial region. The caudal part of the endocranial region is occupied by the large, teardrop-shaped cerebral fossa that faces medioventrally. This fossa was misidentified as the olfactory bulb fossa by McDonald et al. (2018) and Yun (2020c). The olfactory bulb and the cerebral fossae are separated from each other by a thick, cylindrical ridge as in other tyrannosaurids (Carr, 2020). McDonald et al. (2018) misidentified this ridge as the ethmoid scar.

Rostral surface: The medialmost part of the rostral surface is the nasal process, which is mediolaterally narrow and tapers at the rostral end (Fig. 5a, b). The mediolaterally narrow nasal process is a derived feature among tyrannosauroids that can be seen only in tyrannosaurines more derived that Alioramini (Carr \& Williamson, 2004, 2010; Yun, 2020c). A depression for the caudolateral process of the nasal is present laterally. More laterally, there is a narrow contact surface for the prefrontal that is bounded by the prefrontonasal process medially and the prefrontolacrimal process laterally (Fig. 5b). The main axis of the contact surface is subvertical dorsoventrally (Fig. 5b) as in other tyrannosaurids such as "Dynamoterror dynastes" (McDonald et al., 2018). However, it differs from Daspletosaurus spp., in which the prefrontal contact surface arches dorsomedially (Voris et al., 2020; Yun, 2020c). Lateral to the prefrontolacrimal process, there is a rostrally facing, deep, cup-shaped lacrimal socket (Fig. 5b), which is similar to sockets found in Gorgosaurus libratus, Daspletosaurus torosus, Nanuqsaurus hoglundi, and some specimens of Tyrannosaurus rex (Currie, 2003a; Fiorillo \& Tykoski, 2014; Yun, 2020c). In Albertosaurus sarcophagus and other specimens of Tyrannosaurus rex, the contact surface for the lacrimal is not socket-shaped (Currie, 2003a). The mediolateral width of the lacrimal socket is wider than its dorsoventral depth, as in Daspletosaurus torosus (Yun, 2020c); however, this differs from the condition in Nanuqsaurus hoglundi, which appears to have a socket that is taller than wide (Fiorillo \& Tykoski, 2014: fig. 4E; Yun, 2020c). A tall sagittal crest - typical of all derived tyrannosaurines (Currie, 2003a; Carr et al., 2017) - can be seen at the dorsomedial part of the rostral surface.

Caudal surface: The medial- most part of the parietal suture, which is the caudal surface of the sagittal crest, is tall and slopes rostrodorsally (Fig. 6a, b). The morphology of this part of the parietal suture represents the median spur of the parietal that separates both frontals caudally, and was broad and triangular in BYU 8120/9396 as it was in other tyrannosaurids such as Albertosaurus sarcophagus (Carr \& Williamson, 2004) and Gorgosaurus li- bratus. In Nanuqsaurus hoglundi and one juvenile specimen of Tarbosaurus bataar (MPC-D 107/7), the spur is narrow and elongate (Tsuihiji et al., 2011; Fiorillo \& Tykoski, 2014). The parietal suture that is positioned caudolateral to the sagittal crest is nearly flat, and its mediolateral axis is slightly inclined rostrolaterally (Fig. 6b). Ventrally, there is a rectangular, rugose laterosphenoid suture that faces caudoventrally. An orbitosphenoid suture is positioned rostromedial to the laterosphenoid suture (Fig. 6b).

\section{DISCUSSION}

Relative maturity and body size of the Teratophoneus curriei holotype individual: Carr et al. (2011) considered the holotype individual of Teratophoneus curriei as a subadult, based on features in the maxilla and the lacrimal that are reminiscent to those of a subadult Gorgosaurus libratus. In this section, characters in the frontal that are relevant to the maturity of an animal are discussed, with the rationale that ontogenetic changes in cranial bones of Teratophoneus curriei are largely similar to those in other tyrannosaurids, including Daspletosaurus torosus (Yun, 2020c) and Tyrannosaurus rex (Carr \& Williamson, 2004; Carr, 2020). Indeed, many studies have demonstrated that the sequence of ontogenetic changes in tyrannosaurid cranial anatomy is fairly conservative within the clade (Carr, 1999, 2010, 2020; Currie, 2003a; Carr \& Williamson, 2004; Brusatte et al., 2012; Lü et al., 2014; Carr et al., 2017). However, it should be emphasized that the results presented here should be considered preliminary as a growth series of Teratophoneus curriei has not yet been described in detail (Titus et al., 2021). Furthermore, at least several species-level taxonomic variations in tyrannosaurid ontogeny have been reported (Carr, 1999; Tsuihiji et al., 2011; Voris et al., 2019; Yun, 2020a, c, 2021).

The nasal process in BYU 8120/9396 is mediolaterally narrow in dorsal view (Fig. 7a), unlike the broad nasal processes in currently known examples of juvenile tyrannosaurines (Carr, 1999, 2020; Carr \& Williamson, 2004; Sereno et al., 2009; Tsuihiji et al., 2011; Yun, 2020c). Instead, narrow nasal processes are known to occur in subadults and adults (Carr \& Williamson, 2004; Carr, 2020; Yun, 2020c; Fig. 7b). Both prefrontonasal and prefrontolacrimal processes in BYU 8120/9396 are distinct, mediolaterally narrow and triangular to spike-shaped (Fig. 7a). In juvenile tyrannosaurines, such processes are either not developed or else are present as stout emarginations (Carr \& Williamson, 2004; Carr, 2020). In this respect, BYU $8120 / 9396$ is similar to similarly sized subadults of Daspletosaurus torosus (SDNHM 32701) and Tyrannosaurus rex (LACM 23845), where the processes in these specimens are narrow and triangular (Carr, 2020; Yun, 2020c). Additionally, prefrontonasal and prefrontolacrimal processes in BYU 8120/9396 are closely spaced when observed in dorsal view, as are the same processes in SDNHM 32701 (Yun, 2020b, c; Fig. 7b). In 


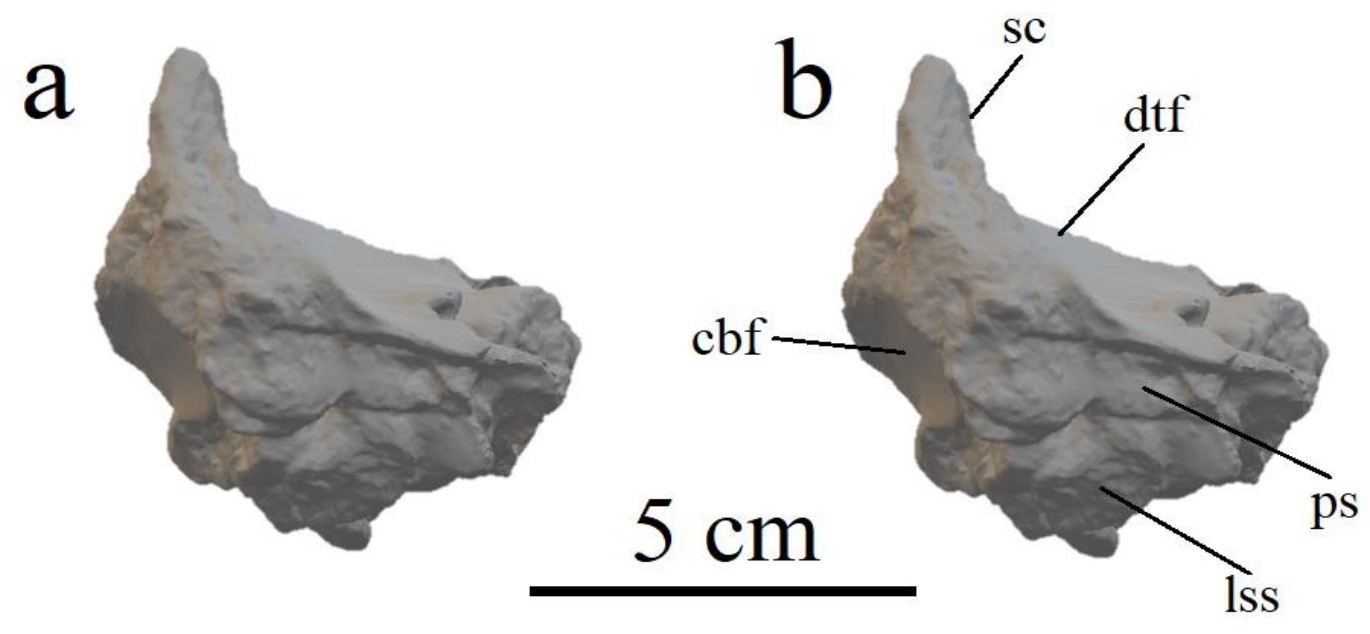

Fig. 6 Stereopair of 3D model of the right frontal of BYU 8120/9396 in caudal view. Abbreviations: cbf, cerebral fossa; dtf, dorsotemporal fossa; Iss, laterosphenoid suture; ps, parietal suture; sc, sagittal crest.

a

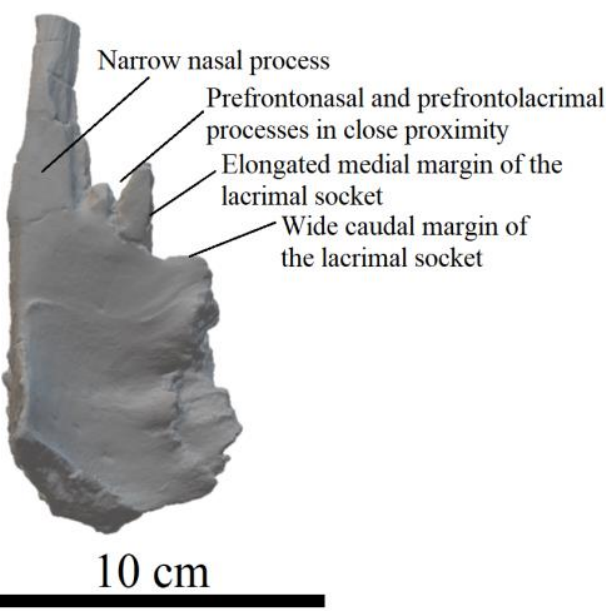

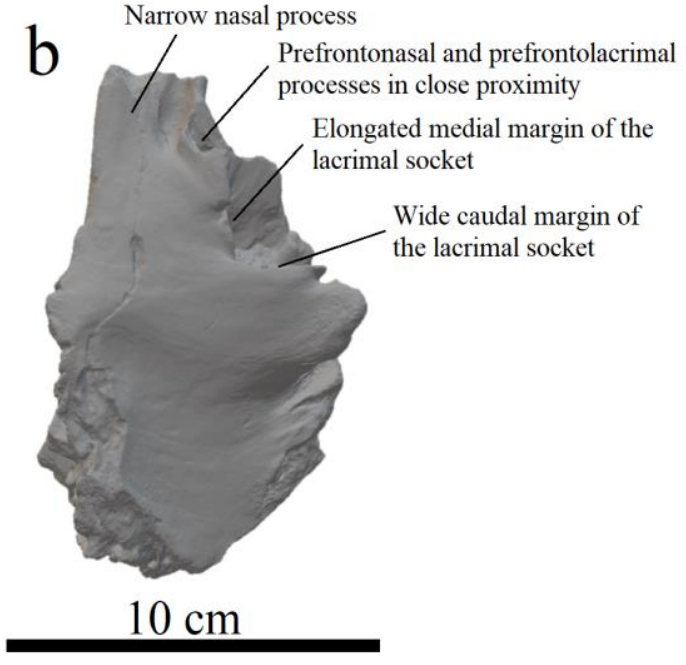

Fig. 7 Comparison of tyrannosaurine frontals in dorsal view, highlighting the characters that are indicative of subadult ontogenetic status. A, 3D model of the right frontal of BYU 8120/9396 Teratophoneus curriei; B, 3D model of the SDNHM 32701, a right frontal of Daspletosaurus torosus.

a subadult Tyrannosaurus rex (LACM 23845), these processes are widely separated from each other (Carr, 2020). In adults of Daspletosaurus torosus and Tyrannosaurus rex, the prefrontonasal and prefrontolacrimal processes are widely separated in dorsal view, and the prefrontolacrimal process is broad and stout (Carr, 2020; Voris et al., 2020: fig. 8; Yun, 2020c). In short, the morphology of prefrontonasal and prefrontolacrimal processes in BYU $8120 / 9396$ is more consistent with it being a subadult rather than a juvenile or an adult.

The medial margin of the lacrimal socket in BYU 8120/9396 is elongate (Fig. 7a), correlated with the elongate prefrontolacrimal process in this specimen. The rostrocaudally elongate medial margin of the lacrimal socket is an immature character among tyrannosaurids (Carr, 1999; Carr \& Williamson, 2004), and it is also present in a similar sized subadult Daspletosaurus torosus (Yun, 2020c; Fig. 7b). Meanwhile, in a similar sized subadult Tyrannosaurus rex (LACM 23845), the same margin is rostrocaudally short that is similar to the conditions found in adults (Carr \& Williamson, 2004; Carr, 2020). Whereas the caudal margin of the lacrimal socket in BYU $8120 / 9396$ is not as mediolaterally wide as in similar sized subadults of Daspletosaurus torosus and Tyrannosaurus rex (Carr \& Williamson, 2004; Yun, 2020c), it is nevertheless much wider compared to the narrow conditions in juvenile tyrannosaurines (Carr \& Williamson, 2004; Tsuihiji et al., 2011; Fig. 7a). Of note, in a similar sized Daspletosaurus torosus (SDNHM 32701), the postorbital buttress is much more developed compared to BYU 8120/9396, possibly reflecting interspecific variation (Fig. 7b). Collectively, the characters in the frontal of BYU 8120/9396 suggest that the holotype individual of Teratophoneus curriei is a subadult, which is consistent with the observations of Carr et al. (2011) on the maxilla and lacrimal of this individual. 
a

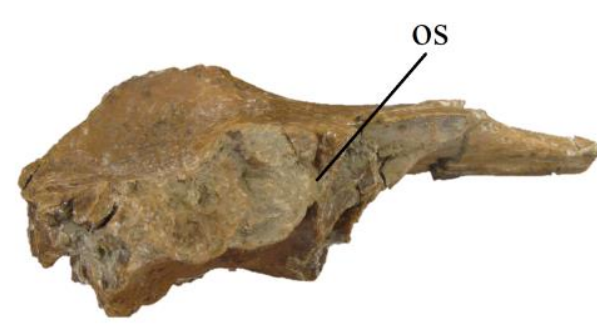

C

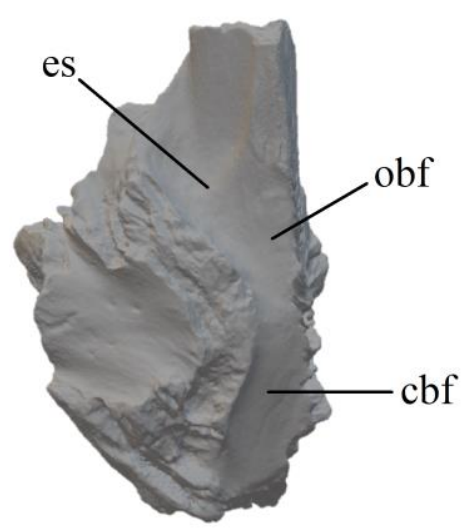

b

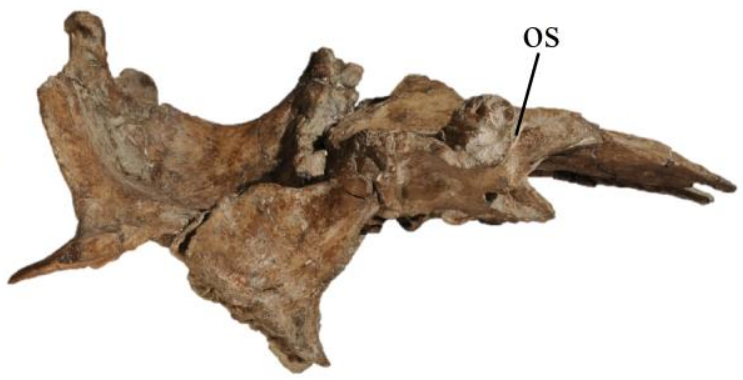

d

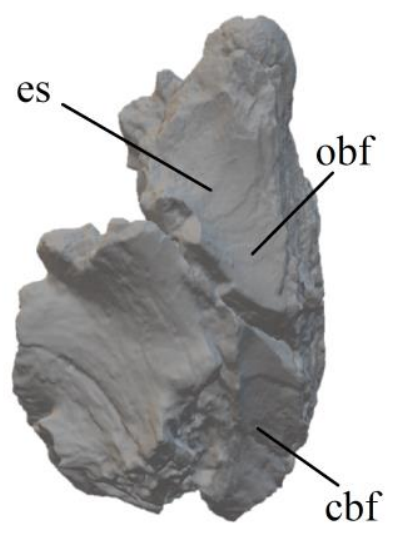

Fig. 8 Frontals of tyrannosaurine theropods, with corrected anatomical interpretations. a, the right frontal of UMNH VP 20200 in lateral view, Lythronax argestes holotype; b, the braincase of UMNH VP 16690 (mirrored) in lateral view, a specimen of Teratophoneus curriei; c, the right frontal of SDNHM 32701 (3D model) in ventral view, a specimen of Daspletosaurus torosus; d, the right frontal of UMNH VP 28348 (3D model) in ventral view, "Dynamoterror dynastes" holotype. Abbreviations: cbf, cerebral fossa; es, ethmoid scar; obf, olfactory bulb fossa; os, orbital slot. Images used in A and B are courtesy of Mark Loewen, and model used in D is courtesy of Western Science Center. Not to scale.

Carr et al. (2011) estimated the body mass of the Teratophoneus curriei holotype individual as $667 \mathrm{~kg}$ based on the femur, although the method used to calculate the body weight is not provided. According to Carr et al. (2011), the circumference of the femur in the Teratophoneus curriei holotype is $266 \mathrm{~mm}$. When this measurement is introduced into an equation proposed by Campione et al. (2014) for estimating total body mass of non-avian bipedal dinosaurs $\left(\log _{10} \mathrm{M}=2.754 \cdot \log _{10} \mathrm{C}-0.683\right.$, where $\mathrm{M}$ is body mass and $\mathrm{C}$ is femoral circumference), which is particularly useful in estimating body masses in tyrannosaurs (Persons et al., 2020), the body mass of the holotype of Teratophoneus curriei is estimated to be 989 $\mathrm{kg}( \pm 25 \%)$. In their report of the bonebed of cf. Teratophoneus curriei, Titus et al. (2021) estimated the body mass and length of the subadult individual within the bonebed as slightly more than $1000 \mathrm{~kg}$ and $6.1 \mathrm{~m}$, respectively. This is based on the frontal bone that is purported to be similar in dimensions to that of the holotype of Lythronax argestes (UMNH VP 20200). The length of the bone between the end of the nasal process and the frontoparietal suture, and the width of the bone between the orbital slot and the interfrontal suture in the right frontal of UMNH VP 20200, are $130.6 \mathrm{~mm}$ and $54.6 \mathrm{~mm}$ respectively. The measurements of the same dimensions in BYU 8120/9396 are very similar, amounting to $106 \%$ and, respectively. $103 \%$ of the values reported for Lythronax argestes. Therefore, it is likely that the body size of the holotype individual of Teratophoneus curriei was similar to that of a subadult individual within the tyrannosaurid bonebed reported by Titus et al. (2021). Thus, it is inferred here that the initial body mass assessment of the holotype individual of Teratophoneus curriei was underestimated, and it is more likely that this individual was heavier, being around $1000 \mathrm{~kg}$ in weight.

\section{Comments on previous literature on tyrannosaurid} frontals: The presence of a well-preserved frontal in the holotype individual of Teratophoneus curriei and its anatomical description gives an opportunity to correct errors that occur in several previous papers that are relevant to tyrannosaurid frontal anatomy. While some errors addressed in this section may simply represent mistakes, especially those caused while generating figures, all of these will be discussed here to provide more accurate information about tyrannosaurid frontals, or those in theropods as a whole. In the description of LACM 23845 by Carr \& Williamson (2004), the dorsal view of the skull roof (their figure 8) correctly shows the contact surfaces with the lacrimals and nasals, but the rostral part of the 
postorbital suture is incorrectly labeled as the surface for the lacrimal in figure 15 from the same publication. When corrected, the region that contacted the lacrimal is located rostromedially, and it is mediolaterally wide and rostrocaudally short (Carr \& Williamson, 2004: fig. 15C, D).

In their description of a tyrannosaurid specimens from the Aguja Formation, Lehman \& Wick (2012) described a foramen-like opening that is positioned caudomedially on the ventral surface of one frontal specimen (TMM 459051) as a sinus cavity. They interpreted this as a possible unique feature for this unnamed taxon as they considered that other tyrannosaurids lack such a feature, although they also speculated that this might be a preservational artifact. In fact, this foramen (see Lehman \& Wick, 2012: fig. 4D) is located in exactly the same region where the orbitosphenoid suture is present in other tyrannosaurid frontals, including BYU 8120/9396. This suture is rounded and foramen-like (McDonald et al., 2018; Yun, 2020c). In fact, it is notable that the literature Lehman \& Wick (2012) referred to in their description of TMM 45905-1 either do not show the ventral surface of the frontal (Russell, 1970; Currie, 1987), or the orbitosphenoid suture is not labeled (Currie, 2003a; Carr \& Williamson, 2004). Therefore, it seems possible that these authors were unaware of this feature in a tyrannosaurid frontal. Judging from the published figures (Lehman \& Wick, 2012: figs. 3, 4), it is considered here that the sinus cavity identified by Lehman \& Wick (2012) is merely a weathered orbitosphenoid suture.

In the description of the holotype specimen (UMNH VP 20200) of Lythronax argestes (Loewen et al., 2013), the anatomical parts of the frontal are correctly labeled in dorsal view on their figure 2 . However, the rostral part of the postorbital suture is incorrectly labeled as the orbital slot (=supraorbital groove) in the lateral view of the same element. In reality, the orbital slot is a vertical groove that grades into the orbit lateroventrally, and is located rostral to the postorbital suture (Fig. 8a). Similarly, in the same paper (Loewen et al., 2013) the label of the orbital slot is incorrectly placed at the lacrimal socket in the dorsal and lateral figures of the braincase of the Teratophoneus curriei specimen (UMNH VP 16690). When corrected, the orbital slot should be labeled at the groove that is mediolateral to this region (Fig. 8b).

In the description of the braincase of Murusraptor, Paulina-Carabajal \& Currie (2017) figured a braincase (TMP 1980.016.0924) of Daspletosaurus torosus(Currie, 2003a; Voris et al., 2020) in dorsal and ventral views in their figure 5. Unfortunately, the lacrimal socket is mislabeled as the contact surface for the prefrontal and the orbitosphenoid suture is incorrectly labeled as the rostral part of the laterosphenoid suture.

In their description of UMNH VP 28348, the holotype of "Dynamoterror dynastes", McDonald et al. (2018) interpreted the horizontal, ridge-like region that is medial to the midlength of the crista cranii as the ethmoid scar. They considered fossae that are rostral and caudal to ridge as the caudal extent of the nasal cavity, and the fossa for the olfactory bulb, respectively. However, as in other theropods (e.g., Evans et al., 2017), the olfactory bulb fossa on a tyrannosaurid frontal bone is actually rostromedial to the crista cranii, and the ethmoid scar marks the rostral margin of it (Osborn, 1912; Ali et al., 2008; Bever et al., 2013). Indeed, a weak ridge is present on the right frontal of UMNH VP 28348 in the region where the ethmoid scar of a tyrannosaurid frontal is typically expected (Ali et al., 2008; Bever et al., 2013). Therefore, it is reinterpreted here that the caudal part of the nasal cavity of McDonald et al. (2018) is actually the fossa for the olfactory bulb that is defined by the ethmoid scar rostrolaterally, whereas the "olfactory bulb fossa" of McDonald et al. (2018) is a misidentified cerebral fossa (Fig. 8d). Thus, no ethmoid scar is preserved on the left frontal of UMNH VP 28348. Yun (2020c) made a largely similar mistake in the description of Daspletosaurus torosus frontal (SDNHM 32701) while referring to McDonald et al. (2018) as the source of this interpretations. The region that Yun (2020c) identified as the olfactory bulb fossa is the cerebral fossa, and the real olfactory bulb fossa is located rostral to it (Fig. 8c).

Comments on the holotype of Nanuqsaurus hoglundi: The holotype of Nanuqsaurus hoglundi (DMNH 21461; Fiorillo \& Tykoski, 2014), recovered from the Prince Creek Formation on the North Slope of Alaska, consists of the partial skull roof as well as fragments of the maxilla, laterosphenoid and dentary, of a tyrannosaurine theropod. Initially, this specimen was described as an adult individual that is diminutive for a tyrannosaurid, being significantly smaller than adults of Albertosaurus sarcophagus and Tyrannosaurus rex (Fiorillo \& Tykoski, 2014). While the exact estimates of body size of Nanuqsaurus hoglundi were not provided in Fiorillo \& Tykoski (2014), Paul (2016) estimated the body length and mass of this taxon as $5 \mathrm{~m}$ and $500 \mathrm{~kg}$, respectively. Originally, Fiorillo \& Tykoski (2014) concluded that this taxon is closer to the Tyrannosaurus rex + Tarbosaurus bataar clade than to any other North American tyrannosaurid. However, later phylogenetic analyses have placed this taxon closer to Teratophoneus curriei (Brusatte \& Carr, 2016; Carr et al., 2017). Subsequent publications have raised questions on parts of the conclusions of Fiorillo \& Tykoski (2014). Paul (2016) noted that Nanuqsaurus hoglundi is based on inadequate material, but nevertheless retained the taxon as valid in light of the possibility that it is a diminutive tyrannosaurid. Later, Druckenmiller et al. (2021) disputed the claim that Nanuqsaurus hoglundi is a diminutive tyrannosaurid, noting that other tyrannosaurid specimens (such as teeth and isolated postcranial elements) from the Prince Creek Formation suggest adult sizes more comparable to Albertosaurus sarcophagus.

Here, additional commentaries are made about the holotype of Nanuqsaurus hoglundi because this taxon was erected mainly on frontoparietal characters, and possibly 
represents a close relative of Teratophoneus curriei. Fiorillo \& Tykoski (2014) do not detail the ways the supposed skull length $(600 \mathrm{~mm}$ to $700 \mathrm{~mm})$ and body size were estimated for DMNH 21461. In fact, estimating the body size of a theropod based on three cranial fragments could represent a difficult endeavor, and it is generally assumed that appendicular bones offer better proxies for size or mass estimations. Furthermore, theropods show a significant amount of intraspecific variation in the proportions of maxillae that form a large part of the snout. Snout length and variability has thus a major influence on the estimated overall length of the skull (Carpenter, 2010), and tyrannosaurids are no exceptions to this (Carpenter, 1990; Carr \& Williamson, 2000). Complete maxillary tooth row length and several other cranial measurements have been shown to have close correlations with the lengths of postcranial elements such as the femur (Currie 2003b). Unfortunately, the description of the holotype of Nanuqsaurus hoglundi does not include any dimensions that can be used to calculate postcranial measurements.

The measurements of the right frontal in DMNH 21461 provided in Fiorillo \& Tykoski (2014) are similar to those of LACM 23845, a subadult specimen of Tyrannosaurus rex (Currie, 2003a; Carr \& Williamson, 2004) especially in its width and depth. If the skulls and the body sizes of the individuals that DMNH 21461 and LACM 23845 represent were largely similar, and they would have been about $9 \mathrm{~m}$ long according to Molnar (1980), as the size of LACM 23845 is about $80 \%$ of an adult Tyrannosaurus rex. Of note, McDonald et al. (2018) obtained a similar estimate of the body length for the holotype individual of "Dynamoterror dynastes" using the same method. Estimated body sizes for Albertosaurus sarcophagus, Gorgosaurus libratus and Daspletosaurus torosus are also approximately about $9 \mathrm{~m}$ long (Russell, 1970; Holtz, 2004). Furthermore, the dimensions of the right frontal in DMNH 21461 (Fiorillo \& Tykoski, 2014) are also similar to those of BYU 8120/9396. If the size estimate made in this paper for BYU 8120/9396 is correct, it would also suggest a body mass for DMNH 21461 of around 1000 $\mathrm{kg}$, which is significantly more than the estimate $(500 \mathrm{~kg})$ made by Paul (2016). Furthermore, Fiorillo \& Tykoski (2014) based their adult ontogenetic status assessment for DMNH 21461 in part on the peg-in-socket like nasomaxillary suture. However, this feature is insufficient to support such a conclusion as a subadult Tyrannosaurus rex individual (LACM 23845) has now been found to also possess such a sutural morphology (Carr, 2020). A similar situation is also known for TMM 41436-1 ( $\mathrm{S}$. Wick, pers. comm. to C.-G. Yun, 2021), an isolated maxilla specimen that is considered as a subadult Tyrannosaurus rex by Carr (2020). In summary, while the arguments presented here may not provide conclusive evidence to reject a diminutive body size hypothesis for Nanuqsaurus hoglundi, they at least urge that great caution is needed when making a body size estimate based on fragmentary remains, as different approaches used by different authors may yield significantly different results. Additionally, the current diagnosis of Nanuqsaurus hoglundi deserves some consideration. One autapomorphy proposed by Fiorillo \& Tykoski (2014) is the presence of a narrow, rostrally forked median spur of the parietals that separates the frontals caudally. However, a high degree of intraspecific variation of this region is present in adults of Tyrannosaurus rex, in which some specimens bear a wedge-like spur on the midline of the rostral margin of the parietals, while others only show a limited invasion of the parietals between the frontals (Carr, 2020). Additionally, the morphology of the median spur of the parietals is subject to ontogenetic variation in tyrannosaurids, as juveniles of Alioramus remotus, Gorgosaurus libratus and Tyrannosaurus rex have narrow, "finger-like" spurs differing from the condition seen in larger specimens (Carr \& Williamson, 2004; Bever et al., 2013; Voris, 2018). In a juvenile Tarbosaurus bataar, the spur is extremely narrow, elongate and rostrally rounded, which gives it a mushroom-like morphology (Tsuihiji et al., 2011). In summary, while the forked rostral end of the median parietal spur in DMNH 21461 might be apomorphic as similar morphology has yet to be reported in other tyrannosaurids, its diagnostic nature should be regarded as provisional as this region of the skull roof is subject to a high degree of individual or ontogenetic variation in this clade, a caution especially important since the ontogenetic status in DMNH 21461 is not certain.

Another proposed autapomorphy of this taxon is the presence of an elongate prefrontolacrimal process. This feature is present in BYU 8120/9396, and even Fiorillo \& Tykoski (2014) acknowledged its presence in Teratophoneus curriei. It is also possible that Lythronax argestes had a similar condition (Loewen et al., 2013: fig. 5C; Voris et al., 2020). Nevertheless, this feature was proposed as an autapomorphy of this taxon; as Nanuqsaurus hoglundi was originally considered as a tyrannosaurine close to the Tyrannosaurus rex + Tarbosaurus bataar clade (Fiorillo \& Tykoski, 2014), this character was regarded as independently evolved (R. Tykoski, pers. comm. to C.-G. Yun, 2021). Later analyses have placed Nanuqsaurus hoglundi as the sister taxon of Teratophoneus curriei (Brusatte \& Carr, 2016) or suggested that it occupies a phylogenetic position similar to Lythronax argestes or Teratophoneus curriei (Brusatte \& Carr, 2016; Carr et al., 2017). Such a position may, however, suggest that this character represents a synapomorphy, rather than being independently acquired. Furthermore, as discussed previously, this character could be individually variable. Therefore, it is rejected as an autapomorphy of Nanuqsaurus.

The last autapomorphy proposed by Fiorillo \& Tykoski (2014) is the presence of the two mesialmost dentary teeth that are significantly smaller than more caudal ones. However, this character is incredibly tenuous, as it is very common among non-avian theropods that show substantial degree of intraspecific variation in teeth/alveoli size, 
variation present even within the two jaws of a single individual. For example, in some specimens of Allosaurus (such as YPM 4944) the second premaxillary tooth is slightly longer (less than $1 \mathrm{~mm}$ ) than the third one in their basal part, while in others (e.g., left premaxilla of CM 21703) the third one is significantly longer (about $3 \mathrm{~mm}$ ) than the second tooth (Hendrickx et al. 2015). In one specimen of Ceratosaurus (UMNH VP 7819), a first premaxillary tooth is $1.8 \mathrm{~mm}$ longer than the third one in the left premaxilla whereas on the right side, the third tooth is approximately $2.4 \mathrm{~mm}$ longer than the first (Hendrickx et al. 2015). In fact, a largely similar case is known in the taxonomic history of Tyrannosaurus: Larson (2008) referred to some adult Tyrannosaurus specimens (AMNH 5027, MOR 008, SDSM 12047 ) as an informal species (Tyrannosaurus "x") distinct from Tyrannosaurus rex. He noted that these have second dentary teeth that are significantly smaller than the third ones, unlike definite Tyrannosaurus rex specimens (Carr et al., 2017). However, it has been argued that this is insufficient to make a taxonomic distinction, and that these specimens fall within the intraspecific variation of Tyrannosaurus rex (Carr, 2020). Hence, this feature might be another inadequate character to be used for diagnosis, especially given the polyphyodont nature of theropods and their observed high degree of intraspecific variation.

In summary, while Nanuqsaurus hoglundi could be provisionally retained as a valid taxon using one potential autapomorphy ("thin, rostrally-forked, median spur of the fused parietals on the dorsal skull roof that overlaps and separates the frontals within the sagittal crest"), the highly incomplete nature of the holotype means that the hypothesis according to which it is a diminutive tyrannosaurid taxon adapted to the resource constraints of a highlatitude ecosystem (Fiorillo \& Tykoski, 2014) and, perhaps, even its taxonomic status should be treated with extreme caution. Description of additional tyrannosaurid material from the Prince Creek Formation (Druckenmiller et al., 2021) is necessary to clarify these issues.

\section{CONCLUSIONS}

A right frontal bone of the holotype individual of Teratophoneus curriei is described in detail. In general, the frontal anatomy of Teratophoneus curriei is largely similar to that of other tyrannosaurids. Some minor differences are present, including an elongate prefrontolacrimal process that distinguishes this taxon from other North American tyrannosaurines like Daspletosaurus torosus and Tyrannosaurus rex. Additionally, the main body of the frontal of Teratophoneus curriei is not as transversely wide as that of the similar-sized Daspletosaurus torosus and Tyrannosaurus rex. The morphology of the frontal is consistent with the subadult status of the holotype individual. This is indicated by other cranial bones as well, although the initial body size estimate of this individual was likely underestimated. Finally, the detailed descrip- tion of the Teratophoneus curriei frontal allows the correction of erroneous informations presented in previous papers about tyrannosaurid frontals, including the biological hypotheses and autapomorphies proposed for Nanuqsaurus hoglundi.

\section{ACKNOWLEDGEMENTS}

The author would like to thank Rodney Scheetz for permission to conduct this research, and for sharing a scan of BYU 8120/9396. Kesler Randall allowed the author to study SDNHM 32701 and shared a scanned file of the specimen, and the author is truly grateful for this. Special thanks go to Lawrence Witmer for his clarifications concerning the extent of the endocranial space on the ventral surface of tyrannosaurid frontal bones. Discussions with Ron Tykoski about the Nanuqsaurus hoglundi holotype were interesting and helpful. Steven Wick provided information about the morphology of the nasomaxillary suture of TMM 41436-1. Mark Loewen graciously shared photographs of frontals UMNH VP 16690 and UMNH VP 20200 in lateral view. The 3D models of BYU 8120/9396 and SDNHM 32701 are courtesy of Brigham Young University Museum of Paleontology and the San Diego Natural History Museum, respectively. This paper benefited from the review comments of Steven Jasinski and Philip J. Currie, and the editorial comments of Zoltan Csiki-Sava. Lastly, the author wishes to express his personal thanks to Dong-Geun Lee for his support and care.

\section{REFERENCES}

Ali, F., Zelenitsky, D.K., Therrien, F. \& Weishampel. D.B., 2008. Homology of the ethmoid complex of tyrannosaurids and its implications for the reconstruction of the olfactory apparatus of non-avian theropods. Journal of Vertebrate Paleontology, 28: 123133.

Averianov, A., 2016. Frontal bones of non-avian theropod dinosaurs from the Upper Cretaceous (SantonianCampanian) Bostobe Formation of the northeastern Aral Sea region, Kazakhstan. Canadian Journal of Earth Sciences, 53: 168-175.

Bever, G.S., Brusatte, S.L., Carr, T.D., Xu, X., Balanoff, A.M. \& Norell, M.A., 2013. The braincase anatomy of the Late Cretaceous dinosaur Alioramus (Theropoda: Tyrannosauroidea). Bulletin of the American Museum of Natural History, 376: 1-72.

Brochu, C.A., 2003. Osteology of Tyrannosaurus rex: Insights from a nearly complete skeleton and highresolution computed tomographic analysis of the skull. Journal of Vertebrate Paleontology, 22(Supplement 4): 1-138.

Brusatte, S. L. \& Carr, T.D., 2016. The phylogeny and evolutionary history of tyrannosaurid dinosaurs. Scientific Reports, 6:20252.

Brusatte, S.L., Carr, T.D. \& Norell, M.A., 2012. The osteology of Alioramus, a gracile and long-snouted ty- 
rannosaurid (Dinosauria: Theropoda) from the Late Cretaceous of Mongolia. Bulletin of the American Museum of Natural History, 366: 1-197.

Brusatte, S.L.,Norell, M.A., Carr, T.D., Erickson, G.M., Hutchinson, J.R., Balanoff, A.M., Bever, G.S., Choiniere, J.N., Makovicky, P.J. \& Xu, X., 2010. Tyrannosaur Paleobiology: New Research on Ancient Exemplar Organisms. Science, 329:1481-1485. DOI: 10.1126/science.1193304.

Campione, N.E., Evans, D.C., Brown, C.M. \& Carrano, M.T., 2014. Body mass estimation in non-avian bipeds using a theoretical conversion to quadruped stylopodial proportions. Methods in Ecology and Evolution, 5:913-923.

Carpenter, K., 1990. Variation in Tyrannosaurus rex. In: Carpenter, K. \&Currie, P.J. (eds.) Dinosaur Systematics: Approaches and Perspectives (pp. 141-145). Cambridge University Press, Cambridge.

Carpenter, K., 2010. Variation in a population of Theropoda (Dinosauria): Allosaurus from the ClevelandLloyd Quarry (Upper Jurassic), Utah, USA. Paleontological Research, 14: 250-259.

Carr, T. D., 1999. Craniofacial ontogeny in Tyrannosauridae (Dinosauria, Coelurosauria). Journal of Vertebrate Paleontology, 19:497-520.

Carr, T.D., 2005. Phylogeny of Tyrannosauroidea (Dinosauria: Coelurosauria) with special reference to North American forms. Ph.D. Dissertation, University of Toronto, Ontario, $1170 \mathrm{pp}$.

Carr, T. D., 2010. A taxonomic assessment of the type series of Albertosaurus sarcophagus and the identity of Tyrannosauridae (Dinosauria, Coelurosauria) in the Albertosaurus bonebed from the Horseshoe Canyon Formation (Campanian-Maastrichtian, Late Cretaceous). Canadian Journal of Earth Sciences, 47: 1213-1226.

Carr, T.D., 2020. A high resolution growth series of $T y$ rannosaurus rex obtained from multiple lines of evidence. PeerJ, 8: e9192.

Carr, T.D. \& Williamson, T.E., 2000. A review of Tyrannosauridae (Dinosauria, Coelurosauria) from New Mexico. New Mexico Museum of Natural History and Science Bulletin, 17: 113-146.

Carr, T.D. \& Williamson, T.E., 2004. Diversity of late Maastrichtian Tyrannosauridae (Dinosauria: Theropoda) from western North America. Zoological Journal of the Linnean Society, 142: 479-523.

Carr, T.D. \& Williamson, T.E., 2010. Bistahieversor sealeyi, gen. et sp. nov., a new tyrannosauroid from New Mexico and the origin of deep snouts in Tyrannosauroidea. Journal of Vertebrate Paleontology, 30: $1-16$.

Carr, T.D., Williamson, T.E., Britt, B.B. \& Stadtman, K., 2011. Evidence for high taxonomic and morphometric tyrannosauroid diversity in the Late Cretaceous (Late Campanian) of the American Southwest and a new short-skulled tyrannosaurid from the Kaiparowits formation of Utah. Naturwissenschaften, 98: 241246.

Carr, T.D., Varricchio, D.J., Sedlmayr, J.C., Roberts, E.M. \& Moore, J.R., 2017. A new tyrannosaur with evidence for anagenesis and a crocodile-like facial sensory system. Scientific Reports, 7: 44942.

Currie, P.J., 1987. Theropods of the Judith River Formation of Dinosaur Provincial Park, Alberta, Canada. Tyrrell Museum of Palaeontology, Occasional Papers in Palaeontology, 3: 52-60.

Currie, P.J., 2003a. Cranial anatomy of tyrannosaurid dinosaurs from the Late Cretaceous of Alberta, Canada. Acta Palaeontologica Polonica, 48: 191-226.

Currie, P.J., 2003b. Allometric growth in tyrannosaurids (Dinosauria: Theropoda) from the Upper Cretaceous of North America and Asia. Canadian Journal of Earth Sciences, 40: 651-665.

Delcourt, R. \& Grillo, O.N., 2018. Tyrannosauroids from the Southern Hemisphere: Implications for biogeography, evolution, and taxonomy. Palaeogeography, Palaeoclimatology, Palaeoecology, 511: 379-387.

Druckenmiller, P.S., Erickson, G.M., Brinkman, D., Brown, C.M. \& Eberle, J.J., 2021. Nesting at extreme polar latitudes by non-avian dinosaurs. Current Biology. doi:10.1016/j.cub.2021.05.041

Evans D.C., Cullen, T.M., Larson, D.W. \& Rego, A., 2017. A new species of troodontid theropod (Dinosauria: Maniraptora) from the Horseshoe Canyon Formation (Maastrichtian) of Alberta, Canada. Canadian Journal of Earth Sciences, 54: 813-826.

Fiorillo, A.R. \& Tykoski, R.S., 2014. A diminutive new tyrannosaur from the top of the world. PLoS ONE, 9: e91287.

Hendrickx, C., Mateus, O. \& Araújo, R., 2015. The dentition of megalosaurid theropods. Acta Palaeontologica Polonica, 60:627-642.

Holtz, T.R., Jr., 2004. Tyrannosauroidea. In: Weishampel, D.B., Dodson, P. \& Osmólska, H. (eds.) The Dinosauria: Second Edition (pp. 111-136). University of California Press, Berkeley.

Hurum, J.H. \&Sabath, K., 2003. Giant theropod dinosaurs from Asia and North America: Skulls of Tarbosaurus bataar and Tyrannosaurus rex compared. Acta Palaeontologica Polonica, 48: 161-190.

Jasinski, S.E., 2015. A new dromaeosaurid (Theropoda: Dromaeosauridae) fromthe Late Cretaceous of New Mexico. New Mexico Museum of Natural History and Science Bulletin,67: 79-87.

Larson, P., 2008. Variation and sexual dimorphism in Tyrannosaurus rex. In: Larson, $\mathrm{P}$ \&Carpenter, $\mathrm{K}$. (eds.) Tyrannosaurus rex: The Tyrant King (Pp. 102128). Indiana University Press, Bloomington, Indiana.

Lehman, T.M. \& Wick, S.T., 2012. Tyrannosauroid dinosaurs from the Aguja Formation (Upper Cretaceous) of Big Bend National Park, Texas. Earth and Environmental Science Transactions of the Royal Society of Edinburgh, 103: 471-485. 
Loewen, M.A., Irmis, R.B., Sertich, J.W., Currie, P.J. \& Sampson, S.D., 2013. Tyrant dinosaur evolution tracks the rise and fall of Late Cretaceous oceans. PLoS ONE, 8: e79420.

Longrich, N.R., 2008. A new, large ornithomimid from the Dinosaur Park Formation of Alberta, Canada: implications for the study of dissociated dinosaur remains.Palaeontology,51: 983-997.

Lü, J, Yi, L., Brusatte, S.L., Yang, L., Li, H. \& Chen, L. 2014. A new clade of Asian Late Cretaceous longsnouted tyrannosaurids. Nature Communications, 5: 3788 .

McDonald, A.T., Wolfe, D.G. \& Dooley, A.C., 2018. A new tyrannosaurid (Dinosauria: Theropoda) from the Upper Cretaceous Menefee Formation of New Mexico. PeerJ, 6: e5749.

Molnar, R.E., 1980. An albertosaur from the Hell Creek Formation of Montana. Journal of Paleontology, 54:102-108.

Osborn, H.F., 1906. Tyrannosaurus, Upper Cretaceous carnivorous dinosaur (Second communication). Bulletin of the American Museum of Natural History, 22:281-296.

Osborn, H.F., 1912. Crania of Tyrannosaurus and Allosaurus. Memoirs of the American Museum of Natural History, 1: 1-30.

Paul, G.S., 2016. The Princeton Field Guide to Dinosaurs: Second Edition. Ed. Princeton University Press, Princeton, $360 \mathrm{pp}$.

Paulina-Carabajal, A. \& Currie, P.J., 2017. The braincase of the theropod dinosaur Murusraptor: osteology, neuroanatomy and comments on the paleobiological implications of certain endocranial features. Ameghiniana, 54:617-640.

Paulina-Carabajal, A., Currie, P.J., Dudgeon, T.W., Larsson, H.C. \& Miyashita, T., 2021. Two braincases of Daspletosaurus (Theropoda: Tyrannosauridae): anatomy and comparison. Canadian Journal of Earth Sciences, 58: 885-910.

Persons, W.S., Currie, P.J. \& Erickson, G.M., 2020. An older and exceptionally large adult specimen of $T y$ rannosaurus rex. Anatomical Record, 303: 656-672.

Schneider, C.A., Rasband, W.S. \& Eliceiri, K.W., 2012. NIH Image to ImageJ: 25 years of image analysis. Nature Methods, 9: 671-675.

Sereno, P.C., Tan, L., Brusatte, S.L., Kriegstein, H.J., Zhao, X. \& Cloward, K., 2009. Tyrannosaurid skeletal design first evolved at small body size. Science, 326: 418-422.
Titus, A.L., Knoll, K., Sertich, J.J.W., Yamamura, D., Suarez, C.A., Glasspool, I.J., Ginouves, J.E., Lukacic, A.K. \& Roberts, E.M., 2021. Geology and taphonomy of a unique tyrannosaurid bonebed from the upper Campanian Kaiparowits Formation of southern Utah: implications for tyrannosaurid gregariousness. PeerJ, 9:e11013

Tsuihiji, T., Watabe, M., Tsogtbaatar, K., Tsubamoto, T., Barsbold, R., Suzuki, S., Lee, A.H., Ridgely, R.C., Kawahara, Y. \& Witmer, L.M., 2011. Cranial osteology of a junivele specimen of Tarbosaurus bataar (Theropoda, Tyrannosauridae) from the Nemegt Formation (Upper Cretaceous) of Bugin Tsav, Mongolia. Journal of Vertebrate Paleontology, 31:497-517.

Voris, J.T., 2018. Cranial Anatomy and Ontogeny of Gorgosaurus libratus (Tyrannosauridae: Albertosaurinae). Master's Thesis, University of Calgary, Calgary, 115 pp.

Voris, J.T., Zelenitsky, D.K., Therrien, F. \& Currie, P.J., 2019. Reassessment of a juvenile Daspletosaurus from the Late Cretaceous of Alberta, Canada with implications for the identification of immature tyrannosaurids. Scientific Reports, 9: 17801.

Voris, J.T., Therrien, F., Zelenitsky, D.K., \& Brown, C.M., 2020. A new tyrannosaurine (Theropoda: Tyrannosauridae) from the Campanian Foremost Formation of Alberta, Canada, provides insight into the evolution and biogeography of tyrannosaurids. Cretaceous Research, 110: 104388.

Yun, C.-G., 2020a. An exceptionally small juvenile Gorgosaurus libratus (Dinosauria: Theropoda) specimen from the Dinosaur Park Formation (Campanian) of Alberta. The Mosasaur, 11: 107-115.

Yun, C.-G., 2020b. A reassessment of the taxonomic validity of Dynamoterror dynastes (Theropoda: Tyrannosauridae). Zoodiversity, 54: 259-264.

Yun, C.-G., 2020c. A Subadult Frontal of Daspletosaurus torosus (Theropoda: Tyrannosauridae) from the Late Cretaceous of Alberta, Canada with implications for Tyrannosaurid Ontogeny and Taxonomy. PalArch's Journal of Vertebrate Palaeontology, 17: 1-13.

Yun, C.-G., 2021. A juvenile metatarsal of cf. Daspletosaurus torosus: Implications for ontogeny in tyrannosaurid theropods. Acta Palaeontologica Romaniae, $17: 15-22$. 